\title{
Consequentialism and Its demands: The Role of Institutions
}

\begin{abstract}
It isn't saying much to claim that morality is demanding; the question, rather, is: can morality be so demanding that we have reason not to follow its dictates? According to many, it can, if that morality is a consequentialist one. This paper takes the plausibility and coherence of this objection - the Demandingness Objection - as a given. Our question, therefore, is how to respond to the Objection. We put forward a response that we think has not received sufficient attention in the literature: institutional consequentialism. This is a consequentialist view that, however, requires institutional systems, and not individuals, to follow the consequentialist principle. We first introduce the Objection, then explain the theory of institutional consequentialism and how it responds to the objection. In the remainder of the paper, we defend the view against potential objections.
\end{abstract}

Keywords. Consequentialism, institutions, demandingness, two-level consequentialism, global justice

\section{The Demandingness Objection to consequentialism}

It isn't saying much to claim that morality is demanding; the question, rather, is: can morality be so demanding that we have reason not to follow its dictates? According to many, it can, if that morality is a consequentialist one. Why is this?

To answer this question, we need first to understand the target of the complaint. ${ }^{1}$ Actconsequentialism holds that whether an act is morally right, depends only on the valuable consequences of that act. More precisely, in its classical form which we will not question in this paper, promotion of the good is understood as maximization. Thus its single principle, often called the principle of beneficence, gives us the act-consequentialist criterion of rightness: "act in such a way as to produce the best possible consequences." The Demandingness Objection (henceforth: the Objection) originally targeted only utilitarians who

\footnotetext{
${ }^{1}$ To answer this question in full we would also have to spend time on the issue why consequentialism is singled out as the only objectionably demanding moral theory and whether this is correct or not. For a detailed treatment of this issue, see (blinded), on which this section relies in part. In the paper we disregard this aspect of the question.
} 
advocated consequentialism with a welfarist theory of value, that is, a theory that focuses on human welfare, well-being, or happiness as the relevant consequence. However, the Objection can be employed against any form of act-consequentialism (henceforth: consequentialism) that involves maximization (and perhaps against other versions as well).

What exactly does the Objection say? ${ }^{2}$ It is built upon two pillars: one, that consequentialism is excessively demanding and, two, that an adequate morality shouldn't be excessively demanding. Consequentialism requires the agent to promote the good until the point where further efforts would burden the agent as much as they would benefit others. However, the current state of the world is far from ideal: it involves, for example, significant levels of poverty that prevailing levels of charitable donations are insufficient to eradicate. ${ }^{3}$ Given that acting to alleviate poverty is likely to have, in sum, better consequences than pursuing individual goals and projects, it seems unavoidable that, if one accepts consequentialism, one must devote most of one's resources to humanitarian projects. At the same time, most would agree that this cannot be accepted, that people should not be required to sacrifice so much to comply with the demands of morality. This is the second pillar of the Objection. Its function is to ground a constraint on admissible moral theories requiring them to avoid excessive demands. If they do not, the conclusion follows that these theories cannot be ones to follow as our moral guide.

In short, the Objection claims that consequentialism's excessive demands are objectionable. We can put the objection somewhat more formally as making an argument in the following general form:

\footnotetext{
${ }^{2}$ The objection is perhaps most clearly stated by those who oppose it. For an early statement see Sidgwick (1907), p. 87; for a recent statement see Cullity (2004), Chapter 1. For further references see Hooker (2009), p. 162 footnote 4, and Carter (2009), pp. 163-85, as well as the works to be cited later in this section.

${ }^{3}$ Unfortunately, it is easy to cite statistics for this claim. Any report by the WHO, the World Bank, UNICEF, UNDP and so on paints the same dire picture, certainly of the global situation, but also, in most cases, of domestic circumstances. See Pogge (2008: 2-3) for more data and references.
} 
1) Consequentialism makes demand $D$;

2) Demand $D$ is excessive ${ }^{4}$;

Therefore,

3) Consequentialism is excessively demanding;

4) If a moral theory is excessively demanding, then it should be rejected;

Therefore,

5) Consequentialism should be rejected.

This general form acquires a specific reading depending on how the term 'excessive' is interpreted: what in one's view is objectionable about excessive consequentialist demands. In particular, the way we have introduced the objection is compatible with three different versions of premise 2) and a fourth can be added as an often mentioned corollary. On the moral reading, consequentialism is claimed to be wrongfully demanding since it requires agents to make sacrifices that they are not, in fact, morally required to make as they are excessive. On the rational reading, consequentialism is held to be unreasonably demanding since it requires agents to make sacrifices that they do not have decisive reason to make since they are excessive. Third, on the motivational reading, consequentialism is taken to be motivationally overexerting because it pictures agents as moral saints who can bring themselves to do whatever morality asks of them no matter how excessive it is. A fourth, epistemic reading of the objection, holds that consequentialism is epistemically challenging because it requires agents to be (nearly) allknowing when it comes to the consequences of their actions or because it makes agents in some other way severely epistemically disadvantaged (e.g. it requires them to understand a very complex principle or have outstanding computational abilities).

\footnotetext{
${ }^{4}$ We take it that 'excessive' implies 'objectionable'. If one holds that this is not so, then 'excessive' can be changed to 'excessive and therefore objectionable'.
} 
Although it is our contention that a switch in focus on to institutions helps with all four forms of the Objection, in this paper, in the absence of a proper theory of reasons that we could employ, we are not concerned with the rational version of the Objection. ${ }^{5}$ The three other readings we will handle in a bundle, although our focus will be on the moral reading. Yet, it is clear that reducing the excessive moral and epistemic demands on individuals would have positive motivational effects as well, and a theory that is motivationally and epistemically less demanding might also be morally more acceptable (depending on whether a moral code like consequentialism should be capable of being applied in conduct). That these different readings of the Objection are in this way intertwined is also indicated by the fact that premise 2) is typically taken to be driven, at least in part, by intuitions that appear to encompass all three versions.

Let us then take the moral reading of the Objection. From this way of putting the objection, it is clear how one can respond to it: one of the three premises - 1), 2), or 4) - has to be rejected. ${ }^{6}$ This is hardly an option with premise 4) though, since if a moral theory is wrongfully demanding, then that moral theory is false, hence conclusion 5) certainly follows. This leaves us with premises 1) and 2). Premise 2) is normally taken to rely, at least in part, ${ }^{7}$ on an intuition, and can be rejected by either denying the existence of this intuition, or arguing

\footnotetext{
${ }^{5}$ For further discussion of this reading see (blinded). See also Portmore (2011) and Dorsey (2016) for an in-depth treatment. The moral reading is the traditional account of the objection and references in previous footnotes provide the relevant sources; the motivational reading is perhaps most apparent in Wolf (1982). For the epistemic reading one could turn to the debate between subjective and objective consequentialism. See also Smith (1988) and (1989) for a discussion of applicability that pertains to both the motivational and epistemic reading of the objection.

${ }^{6}$ Unless one can show that the argument simply cannot get off the ground. Thus scalar-consequentialists claim that consequentialism makes no demands on us, although it does give us reasons to act. See Norcross (2006); for a response, see McElwee (2011).

${ }^{7}$ We say 'at least in part' because, certainly in the case of the motivational and epistemic reading, the more general applicability constraint that generates these complaints can be driven also by moral or conceptual arguments. See Smith (1989: 117-8) for a good discussion. Similar, theory-laden grounds may be found for the other readings as well, but it is hard to deny their intuitive grounding. See e.g., how Portmore (2011), Chapter 2 introduces the motivation for the rational reading of the Objection or how Bykvist (2009) and Mulgan (2007) spell out the background for the moral version of the Objection by using typical 'intuition-pump' type of examples and fictional cases. It should be noted that Smith also acknowledges the role of common sense in motivating the Objection.
} 
that we have reason not to rely on it. ${ }^{8}$ This won't be the route we take, though. This leaves premise 1) as the only possible target. Rejecting this premise is the perhaps most popular way of responding to the Objection, but we will give it a twist. Instead of either restructuring consequentialism in the usual way or denying the empirical circumstances that give rise to these demands (given the consequentialist principle's application to individual agents), we change the focus of consequentialism from individuals to institutions. ${ }^{9}$ In the next four sections we explain what we have in mind and in subsequent sections we defend it against possible objections. We then end the paper with a summary and some concluding remarks.

\section{Institutional consequentialism}

The core idea of our approach is to direct attention to the ability of institutions to reduce moral demands on individuals. Accordingly, we call our view institutional consequentialism. ${ }^{10}$ Institutional consequentialism adapts a central idea of Rawls's (1971) non-consequentialist theory of social justice to consequentialist morality, defending the following division of labour: the consequentialist principle of beneficence regulates the design of a basic institutional structure, whereas individuals have the duty to set up and maintain these institutions. ${ }^{11}$ This idea clearly goes some way towards tackling the demandingness objection since, arguably, even in our present world, setting up and maintaining consequentialist institutions would be

\footnotetext{
${ }^{8}$ This is often called the extremist strategy, for an overview and critical discussion see Mulgan (2001). There is also a related debate about the use of intuitions in moral theory. See Sandberg \& Juth (2011). Concerning the (widespread) existence of the intuition, see (blinded).

${ }^{9}$ For a discussion of the second, empirical strategy, see Mulgan (2001) and Bykvist (2009). The first approach, the restructuring strategy has given rise to a variety of alternative approaches, some of which regard themselves as consequentialists, others do not. For critical discussion of these views see Mulgan (2001), (2007); Bykvist (2009).

${ }^{10}$ This is not an entirely unprecedented view in the literature. A similar view appears in Goodin (1995), Hardin (1986, 1988) and Bailey (1998), although only Hardin (1988: 126) appears to mention the kind of pluralism we build our theory upon. For mention of the idea in a non-consequentialist framework, see Nussbaum (2007), pp 309-10.

${ }^{11}$ The term 'ethical division of labour' comes from Nagel (1979). See also Nagel (1991) for a more detailed investigation of this Rawlsian thought. We are aware that there are questions to ask about the exact way we understand this division of labour in a consequentialist framework. We discuss these matters in later sections.
} 
not nearly as demanding as applying the principles ourselves. Exactly how demanding it would be, is ultimately an empirical question to be answered with the help of political science, economics, and other social sciences. Below we will introduce some reasons for thinking that our claim is along the right lines. We will in the following section offer reasons for adopting institutional consequentialism that do not solely depend on concerns about (over)demandingness. Next, building in part on these considerations, we will show how institutional consequentialism can help with reducing moral demands on individuals.

However, before this happens, we should say some more about what we take institutions to be. ${ }^{12}$ Although the term institution in a narrower sense can refer to organisations and collective bodies, our usage is broader than this. We follow Rawls $(1999: 47-8,55)$ in focusing on institutions that comprise the basic structure of society ${ }^{13}$ and in regarding an institution as a public system of rules which defines institutional roles with rights and duties attached to them. ${ }^{14}$

The institutions of the basic structure that are in our focus in this paper have a number of further characteristics. First, these institutions are fairly complex social structures. The roles defined by institutional rules hang together as a complex and interdependent system. ${ }^{15}$ Second, institutions are partly constituted by the conduct of individuals upholding them. This is because we take an institution to be existing when a number of people regularly and knowingly follow

\footnotetext{
${ }^{12}$ What follows is adapted from (blinded).

13 The basic structure includes "the political constitution and principal economic and social arrangements". It covers legal rules affecting property and the organization of the economy. Property is determined not only by property law regimes but by a broader set of public norms including contract and commercial law, laws in criminal law against force and fraud, public health law, labour regulations etc. See Rawls (1993: 258, 282-3).

14 Douglass North defines institutions as "humanly devised constraints that shape human interaction." They "structure incentives in human exchange, whether political, social, or economic" (North 1990: 3). In this paper we focus on institutions that comprise the basic structure which, as we shall discuss presently, have additional important characteristics. This narrows the scope of our inquiry, nonetheless, the category of institutions thus understood is still broad enough to include organisations - such as business firms or universities - as well as systems of organisations - such as political systems and capitalist economies - and other institutions that do not involve organisations - such as simple barter economies.

15 The differentiation of roles the institutions of the basic structure embody is one key characteristic that distinguishes these institutions from simpler social forms, such as norms, conventions, and institutions outside the basic structure (Miller 2010: 22-25).
} 
its rules. Rather than considering institutions as abstract objects, i.e. possible forms of conduct expressed by systems of rules, we focus on institutions as actual practices, i.e. the way these rules are realised in the actions of persons. ${ }^{16}$ Finally, many though not all institutions we are concerned with include formal sanctions to enforce their rules. The most important examples of those that do are legal and political systems, and economic institutions. As we shall argue in Section 3., the institutions of the basic structure rely on sanctions in solving collective action problems. $^{17}$

Owing to the basic structure's complexity, both institutional roles and the actions of their occupants are interdependent (Pogge 1989: 8-9). Tasks of one role cannot be successfully undertaken without the performance of tasks associated with other roles in the system (Miller 2010: 24). Furthermore, the outcomes of actions by one institutional player often cannot be considered in isolation from the actions of others. Within the context of the basic institutional structure, the piecemeal ethical evaluation of specific actions, and even specific institutions, risks being inadequate, as it loses sight of the systemic nature of the basic structure (Pogge 1989: 9). To avoid an unduly narrow focus, a consequentialist evaluation of roles and actions in institutional frameworks should consider alternative institutional frameworks in order to account for interdependencies between roles and institutions that different frameworks generate.

\section{Consequentialism and the institutional division of labour}

As discussed by us in more detail elsewhere, an institutional division of labour is supported by reasons which are compatible with the consequentialist goal and are not based on the independent moral status of non-consequentialist values or, in some cases at least, on

\footnotetext{
${ }^{16}$ As our description makes it clear, however, institutions differ from mere patters of actual conduct.

${ }^{17}$ Sanctions also contribute to making institutions self-reinforcing structures.
} 
(over)demandingness considerations (blinded). First, the basic institutional structure performs the function of background adjustment that individuals cannot and should not be expected to make. Second, institutions often determine the content of consequentialist morality for individual agents: they coordinate the collective pursuit of consequentialist goals when individual duties cannot be specified without prior institutional assignment.

Consider, first, the idea of background adjustment. Economic and political institutions enable agents to act on local, often partial, reasons rather than to aim at consequentialist ends. They contribute to the more effective promotion of consequentialist goals by counteracting informational, cognitive and motivational limitations in individual agents. ${ }^{18}$ In particular, they are better equipped to deal with the consequences of individual choices that run into the distant future affecting a large number of individuals ${ }^{19}$. They also correct for our tendency to biases such as self-deception and non-consequentialist motives, removing informational and motivational burdens from individuals in their day-to-day decisions (Smart 1956: 347). For example, markets coordinate decentralized information through the price system, and, when well designed, they structure competition to generate efficient outcomes (Hayek 1976: 20). Background institutions such as markets and legal procedures also facilitate an efficient division of labour in which individual agents with different skill-sets and opportunity costs specialize and exploit their comparative advantages. Frequently, this division of labour takes place within adversarial systems such as markets or courts of justice that are justified by pointing out a division of labour between adversaries leads to best outcomes (Applbaum 1999).

An institutional division of labour is justifiable on consequentialist grounds, then, since the consequentialist goal can be more effectively promoted in an institutional setting with

\footnotetext{
${ }^{18}$ Hardin (1988: 6-9) discusses another type of limit of reason: limitations concerning our value theory. The idea is that we are limited in assessing both utility to ourselves as well as utility to others. These limits have partly to do with the difficulties concerning interpersonal comparisons of value and with the possible non-additivity of value (such as the case of organic wholes).

${ }^{19}$ See Rawls (1993: 266-269) for this point in a non-consequentialist context.
} 
division of labour - adversarial or otherwise - rather than by independent individual actions by agents aiming at promoting the good. The background adjustment by institutions in turn permits and may even require some agents to act on local reasons following, for example, selfinterest in markets and the interests of principals in courts of justice.

Second, besides narrowing the set of factors agents are to consider through a process of background adjustment, the institutional division of labour specifies the content of consequentialist morality for individual agents when individual duties are indeterminate. Institutional rules allocate responsibilities within a larger group. Political and economic institutions notably coordinate the behaviour of large numbers of agents in strategic settings, and they solve collective action problems and implement policies that would otherwise not be implemented.

Interactions between individual agents often take place in strategic settings, when the outcome associated with individual choices depends on the choices of numerous other agents which are in turn influenced by expectations about what the former might do. Institutional rules may be necessary to coordinate strategic interaction such that a group of individuals can achieve a morally required outcome when this is possible only if everyone or a sufficiently large number of people follow the same course (Hardin 1988). Political institutions thus specify underdetermined consequentialist demands by settling a set of responsibilities for agents who would often have no way to determine the right thing to do in the absence of institutions.

In addition to their coordinating function, political institutions solve collective action problems and implement beneficial policies that would otherwise not be implemented. For example, in the face of an incentive to free-ride, institutional rules make the provision of public goods possible by threatening with sanctions against noncompliance and by providing positive incentives encouraging contribution. Authoritative institutions also provide assurance to members of a group that others contribute their share of the collective burden. 
An implication of institutions' role in background adjustment and strategic coordination is that the institutions of the basic structure are subject to different rules when they coordinate, allocate and enforce responsibilities among their participants than the participants themselves. Institutional rules sometimes pre-empt the application of consequentialist reasoning by their subjects and permit or even require reliance on partial considerations, as in the case of economic competition or adversarial systems. Finally, at the extreme, as in the cases of public good provision and perfectly competitive market equilibria, individual duties do not even make sense without prior institutional assignment since by assumption individual actions make no difference to the outcomes.

\section{Institutions and demands}

Given these considerations, institutional consequentialism can help us with the Objection. It does so in (at least) three ways. First, institutions reduce consequentialist demands on individuals by restricting individual contributions to the moral cause to the setting up and maintaining of institutions. Second, institutions economize on the time and attention spent by individuals on the pursuit of consequentialist goals. Third, institutions also remove some of the motivational burdens in making and executing decisions. The first claim speaks directly to the moral reading of the demandingness problematic, the second and the third do so indirectly, via tackling, at least in part, the epistemic and motivational demands of consequentialism. The result, we submit, is that institutions thus allow individuals to lead personal lives. Let us consider each of these claims in turn.

Our first claim is that institutions significantly reduce moral burdens on individuals simply by not requiring them act according to the consequentialist principle but only to set up and maintain institutions that make sure the principle is fulfilled. This claim can be supported by at least three considerations. First, consequentialism is notoriously insensitive to the number 
of those who contribute and this significantly increases the moral burden on individuals. However, well-designed institutions can successfully counteract this by distributing the burden over all individuals, e.g., in the form of taxation, and by making sure that everyone contributes. This leads straight to the second consideration. As noted before, institutions are the best instruments for coordination in strategic settings (Goodin 1995: 67). Individuals cannot ensure that their fellow citizens contribute to the fulfilment of consequentialist aims: this is simply not in their power. However, institutions can both set the target to be achieved and make sure that people contribute to its achievement. They allocate responsibilities and help individuals avoid frustrating one another's attempts at promoting the good, as they would when trying to do the same good deed in an uncoordinated manner. By preventing much waste caused by futile or counterproductive attempts at promoting the good, institutions reduce burdens on individuals. Finally, third, the institutions themselves would be such that they are designed to prevent overburdening those who contribute to their maintenance. Thus, Bailey (1997: 53-4) argues the rationale for designing consequentialist (in his case: utilitarian) institutions is to avoid moral exploitation: situations in which not only aggregate well-being is not optimal but also the utilitarian agent is made worse off. ${ }^{20}$ In our imperfect world, Bailey (Ib.: 147-8) then points out, this translates into the task of making sure that utilitarian agents do not impoverish themselves. In Bailey's view this requires institutions that make sure that utilitarian agents do not have to rush off every time when someone is in need but can instead stand by their posts (be that oneself, one's family or one's projects). In his view, such institutional framework would at least in part consist in a network of substantive and procedural rights (establishing self-ownership and world ownership) as well as reasonable distributive institutions (in particular: a social minimum).

\footnotetext{
${ }^{20}$ Bailey's (1997: 60) main argument for this non-exploitation principle appears to be that without the principle utilitarianism would be self-defeating. Avoiding exploitation, he argues, is an evolutionarily stable strategy, hence without the principle, utilitarians will die out, and the world will be worse off in utility terms.
} 
Our second claim is that institutions allow agents to economize on information and attention. Individuals can take a narrow perspective when they interact with others in institutional settings such as markets and courts, and benefit from an efficient division of labour. Furthermore, institutions can relieve individuals of some informational and cognitive burdens in their charitable contributions as well. Consider the fact that a large part of the consequentialist demands on us are iterative in nature. The particular demand in question is not itself significant, in fact, we can assume that it is rather trivial. Assume, for instance, that due to collective organization, we do not have to give out, at once, a huge sum of money to help the needy, but only a small sum. However, if we have to do this constantly, i.e., if consequentialist demands become too numerous (even if trivial), their intrusion to our life will be constant and objectionably demanding: they will demand our constant attention, not allowing us to get on with our lives. ${ }^{21}$ Institutions can again help with this. They can not only make sure that the amount of our contribution is manageable, but also that we do not have to contribute constantly, i.e., decide how much and to which organization to give to help the needy and then write a check several times a day (Goodin 2009: 9-10). They can do so by, e.g., deducting our contribution from our monthly salary and then distributing it to the relevant agencies on the basis of their reliability and efficiency.

Our third claim is that institutions remove some of the motivational demands of consequentialism from individuals. For one thing, they provide assurance to individual agents that others are going to shoulder their share of the collective moral burden in the face of pervasive moral disagreement and self-interested motives. ${ }^{22}$ Besides changing payoffs associated with existing preferences, institutions can also shape preferences when individual

\footnotetext{
${ }^{21}$ See Cullity (2004) who makes substantial philosophical use of these iterated demands in drawing up the demandingness objection.

${ }^{22}$ Note that this claim is often put as a claim of fairness. See Murphy (2000) for the most complete theory along these lines. However, it is important to keep in mind, and Murphy is clear on this, that the supposed unfairness of consequentialism and its demandingness are two separate issues. If all there is to demandingness is lack of fairness, then there is no real demandingness problematic.
} 
agents cannot do so. Institutions can help 'launder' irrational preferences based on false beliefs

(Goodin 1995: 133). They can also purge antisocial preferences in current and future human beings. For example, institutional pressure, the "naming and shaming" of wrongdoers and institutionalized dialogue can change our personal motivations better to promote the good. Institutional solutions can also help society achieve the consequentialist goal by optimally designing future persons so as to cause them to lead healthier and happier lives, and to have preferences that make the outcome the best in the long run.

The emerging picture, we think, is persuasive enough. Yet, there are possible objections. The most obvious one is that we just don't provide enough ammunition to properly tackle the Demandingness Objection. A natural way to put this is to point out that, at least, on some occasions, individuals will still have the duty to promote the good directly, and that such a duty will be too demanding. ${ }^{23}$ Our answer has to do with what we take to be the correct understanding of the Objection. ${ }^{24}$ We hold that the Objection applies to a theory if that theory is systematically (over)demanding; what needs to be shown is that it can be expected to commonly generate duties to promote the good that are excessively demanding. Hence, whether a theory is excessively demanding is largely an empirical question, and what we've already said and what we are about to say in the next section suffices to show that that the likelihood of excessive demands systematically arising is low. The objection then fails since to show that institutional consequentialism allows for a duty to directly promote the good to come into effect doesn't suffice to show that it is also excessively demanding in the proper sense.

\footnotetext{
${ }^{23}$ Notice that it is not enough to say that individuals will still have the opportunity to promote the good directly on institutional consequentialism. What can make consequentialism excessively demanding is what it requires, not what it permits, individuals to do. In fact, such room for permission can well be considered a virtue of institutional consequentialism since it makes room for supererogation, to mention one thing.

${ }^{24}$ Notice, also, that whether this consequence is correctly ascribed to institutional consequentialism depends on how exactly its structure is worked out: the theory doesn't have to contain a duty to directly promote the good. For example, it could be said that on institutional consequentialism, the right act is the one that is required by the best institutions and/or that makes the biggest positive contribution to bringing about and sustaining the best institutions. However, we shall adopt a version of institutional consequentialism that leaves room for such a duty.
} 
Assuming, then, that our general approach is defensible, we can turn to more specific challenges. The one that comes perhaps first to mind is that institutional consequentialism merely transfers the demandingness problematic to the institutional level: it is now institutions that will be required to do too much. However, there are no psychological, motivational, epistemic or other demands-related problems with institutions, not at least similar to those individuals face (cf. Goodin 1995: 68). The demandingness objection derives its force in large part from the fact that a committed consequentialist individual would not be able to lead a personal life, that his/her individuality would be wiped away by the impersonal requirements of consequentialism. But it does not make much sense to claim that societies and their institutions would face similar fate just because they have to contribute much. It can of course happen that under the pressure of demands an institution turns out to be inadequate to the task. But the way we (would) react to such situation is not moral disapproval, but, assuming we agree with the moral task (which we do here), determination to design better (more efficient, larger etc.) institutions..$^{25}$

The only way, it seems, high contributions required of societies could have seriously negative effects if their members' lives would be affected in a devastating way via the destruction of certain shared social practices that constitutively contribute to their identity. But, first, given the alleviating effect of the division of labour in place, the particular society in question would really have to contribute extraordinarily much in order for such individual effects to threaten. Second, the destructive influence of high societal contributions would have to affect the relevant projects and commitments of people. The fact that as a result of high societal contributions individual members would have to give up certain luxuries of life in order to help suffering others elsewhere, could hardly be persuasive. Finally, third, we do not

\footnotetext{
${ }^{25}$ Of course, institutions are often comprised of individuals, hence one could argue that these public officials' lives would be very negatively affected. But what we say in the text holds also here: the response to this would be to design better institutions, i.e., ones in which such consequences do not occur. Moreover, as we show in the next section, it matters here which version of institutional consequentialism one endorses.
} 
find the idea of social practices being constitutive of one's individual personality plausible. This is after all a distinctively communitarian thought that is subject to the criticism that people can reflect upon and decide about their aims, projects and commitments in life (Kymlicka 2002). Given the good moral reasons in support of the consequentialist cause, it might therefore well be the case that, instead of experiencing the results of high societal contributions as destructive of their personal life, people would see them as more in line with their new, reformed personality (that, though, does not have to be so reformed as to also conform to consequentialism when applied to their actions directly).

However, having said all this, one problem is still looming. It could be pointed out that we have not paid adequate attention to the difference between maintaining (running) and setting up (or even just reforming) an institution. Bailey (1997: 149) identifies two sources of the difference between their respective demands. One, institutional reform typically requires political reform which in turn needs political activism to make sure that the reforms take place. Two, even after the reforms are enacted (e.g. as law), expenditures are needed to get new institutions up and running. As Bailey points out, beside leading to increased demands, both sources are also beset with collective action problems: the costs of setting up institutions typically rest on the shoulders of few but the benefits of institutions once set up are spread throughout society. In short, given all this, even if maintaining an institution is not objectionably demanding, setting up institutions is. ${ }^{26}$

This is a complex (and empirical) matter. To make headway, we must proceed by simplifying things somewhat. In our response, we therefore consider two schematic scenarios

\footnotetext{
${ }^{26}$ There is an interesting parallel between what we say here and Valentini (forthcoming). She argues that in nonideal circumstances the duty to reform unjust institutions or bring about just ones is best based not on Rawls's natural duty of justice but on the duty of beneficence. Valentini's main reason for this is that Rawls's natural duty wouldn't demand enough in such circumstances and we would have to rely on beneficence to take up the slack (as it were). Our brief discussion here could be read as both affirming this idea but also pointing to its limits (Valentini herself doesn't seem to be concerned with (over)demandingness problems, it should be noted).
} 
only. ${ }^{27}$ In one case, there is an already existing, sufficiently well designed and supported institutional framework. In this case, we believe that the above objection does not have sufficient force. In such settings there will be enough initiative and motivation to reform institutions in such a way that burdens are distributed over a high number of individual agents. We should also not forget that institutional systems have a nested structure in which one institution can reform another and in these societies already reformed, well-functioning institutions will be available to help individuals out in their reform endeavours.

The other case is admittedly more difficult. Here we have to imagine the opposite or near the opposite of what we described above. That is, there are no or not enough well designed institutions that could help us reform other institutions; people, moreover, are short-sighted, selfish, and, perhaps, corrupt. To illustrate: We could say that Rawls' (1999) liberal peoples and perhaps some of what he calls decent peoples belong to the first category, whereas burdened societies, rogue (outlaw) and failed states and probably some other illiberal peoples belong here. ${ }^{28}$ In this case, it does seem correct to say that institutional reform is hopeless. Of course, these societies can also change but this happens in radical ways that consist in eradicating and then redesigning the entire institutional system. However, for this very reason it is unlikely that there is a universal consequentialist obligation to fight for institutional reform in these circumstances: given the high likelihood that any such effort would merely be wasted,

\footnotetext{
${ }^{27} \mathrm{We}$ bracket here a further problem for the above objection, namely, that it relies on an illegitimate separation of two kinds of demands and focuses only on one of them. To judge whether institutional consequentialism is excessively demanding, it seems more sensible to consider the two sets of demands - those of maintaining and setting up or reforming institution - together, rather than separately as a limited time-slice view on which the demands of setting up institutions make institutional consequentialism subject to the Objection. This separation loses sight of the possibility, however, that, once the proper institutional setup is in place, the demands on individuals may be significantly reduced.

${ }^{28}$ Rawls (1999: 14-15; 63-78; 80-1) describes liberal and decent peoples as those that meet certain minimum conditions such as respecting basic human rights, regarding the law as embodying a commitment to a "common good idea of justice' and treating their subjects as capable of bearing duties. By contrast, burdened societies are prevented by their lack of economic or cultural resources from becoming well ordered. Outlaw states in Rawlsian terminology are states that are aggressive towards other societies and tend to violate human rights.
} 
the expected utility (or whatever the relevant consequence is) would be too little to ground any proper consequentialist obligation.

\section{Our version of institutional consequentialism}

We hope that the above considerations suffice to make the case for institutional consequentialism as a response to the demandingness objection convincing enough. Assuming that this is so, we will now spend some time on clarifying the exact form of institutional consequentialism.

Our preferred version keeps the original act-consequentialist setting and connects it to the Rawlsian division of labour idea. We think this is best done by endorsing a version of twolevel consequentialism. ${ }^{29}$ That is, institutional consequentialism makes use of the well-known distinction between criterion of rightness and decision-procedure: the former is still given by (maximizing) act-consequentialism, but the latter consists mostly in decision procedures that common-sense morality recognizes - they are those decision-making rules the following of which produce the best consequences overall (Hare 1981; Railton 1984). Now, for reasons given in previous sections, for individuals the perhaps most important such decision rule is to set up and maintain institutions that are designed according to the act-consequentialist principle of beneficence. In short, while the criterion of rightness is the same both for individuals and for institutions, the former are not required to apply the principle of beneficence in their everyday conduct.

However, as it stands, this view is not complete. Institutions, recall, are public systems of rules. Hence it is these rules that are designed according to act-consequentialism. But notice also that at least some of these institutions are run by public officials and in the case of these

\footnotetext{
${ }^{29}$ Goodin (1995: 61-2), Bailey (1997: 24-7), Hardin (1988: 14-7, 100-110) appear to agree, although their use of the term 'rule-consequentialism' is ambiguous between the two readings. The same is true of Mulgan (2007: 126$8)$.
} 
institutions many of the traditional problems of act-consequentialism might reappear (Eggleston 2014: 136-7). In particular, as we saw earlier, act-consequentialism requires huge amount of information regarding the consequences of actions, since it has to reckon with all the consequences of every possible action way out in the unforeseeable future. Although this could be, at least to some extent, counteracted by a division of labour among the officials themselves, decision-making could still be seriously crippled by all the information gathering, processing and constant calculation. Also, act-consequentialism might lead to the breaking down of coordination that we praised above as an advantage of institutional consequentialism. This is because the officials would expect one another not to stick to plans and commitments since, as committed act-consequentialists, they would shirk from these plans as soon as an opportunity with better (expected) consequences arose.

These problems count in favour of introducing decision procedures for public officials that are different from the principle of beneficence that inform the design of the rules that constitute the institutions. In other words, they push us to extend two-level consequentialism to institutional conduct as well insofar as this concerns individual decision-making within the institutions. Moreover, as Goodin (1995: 62-5) persuasively argues, these decision procedures should be general in form allowing only for few exceptions.

To sum up, as two-level institutional consequentialists, we hold that both private citizens and public officials, although their conduct is ultimately evaluated by an actconsequentialist criterion rightness that is also used to design institutions, are to apply general rules that need not be consequentialist and hence need not be the same as the rules that constitute the institutions. For private citizens, the most important decision rule is to set up and maintain institutions; for public officials, there could be any number of rules, among them, especially perhaps on higher administrative levels, the principle of beneficence itself. A caveat is needed here, though. Two-level consequentialist rules are typically considered to be what 
Rawls (1955) calls 'summary rules': heuristic devices, 'rules of thumb' that are to be employed in decision-making only insofar as they do indeed produce the best consequences. If it turns out that they do not, the rules can be broken, an exception created or an entirely different rule employed. ${ }^{30}$ Since we have already admitted that public officials can use the principle of beneficence as a decision rule (albeit, we reckon, rarely), the question naturally arises whether the same is true of private citizens. Our response is that we indeed don't deny that private citizens might, on occasion, resort to directly applying the principle of beneficence but, for the reasons given in preceding sections as well as here, this would rarely happen, if at all. ${ }^{31}$

This is then our general picture of what institutional consequentialism should look like. Of course, two-level consequentialism is anything but an undisputed theory. We do not have the space here to deal with all of its problems but there are two issues that we would like to address since they are relevant for further specifying our understanding of the theory. The first problem is specific to our proposal. It could be claimed that by endorsing two-level consequentialism we are only paying lip service to the idea of a division of labour since, strictly speaking, we do not have different moral principles for individuals and for institutions. Instead, we have the same moral principle, i.e., the same criterion of rightness, but different decision rules. Our answer to this is to bite the bullet: we do not see why this has to be a problem. It is clear that we have a division of labour in place, albeit it is not one that would introduce a rupture into the structure of consequentialism. It would have to be a rupture, it seems, since, on the proposed alternative that is now demanded of us, there would have to be two more codes, one for individuals and one for institutions, and only the latter would be consequentialist.

\footnotetext{
${ }^{30}$ We say 'typically considered' because two-level consequentialists are not restricted to regarding all social rules as rules of thumb. They can support the adoption of legal rules and social practices that do not allow direct application of the consequentialist principle in particular cases. These rules may even penalize actions that do in fact maximize utility. So a second role of institutions in two-level consequentialism is to modify behaviour by changing payoffs and preferences.

${ }^{31}$ How rare these occasions would be, depends on whether the rule to set up and maintain institutions would be part of an ideal or a non-ideal set of decision rules. In the former case, following the rule (jointly, we presume, with other rules) would produce extensional equivalence with the requirements of act-consequentialism; in the latter case, it wouldn't.
} 
Although 'consequentialism' is often considered to be a family resemblance term, such a hybrid theory would be stretching things too far. ${ }^{32}$

The second problem is well-known and general. It is normally put like this. The rules people use in making decisions largely overlap with the publicly affirmed morality of their society. However, on two-level consequentialism, these rules do not constitute the true morality: that is still given by the act-consequentialist criterion of rightness. The question, then, is how to combine these two moralities. One option is to inform people about both moralities and make it clear to them that the rules they use for decision-making are merely 'summary' rules whose function is instrumental to the true consequentialist aim. The problem with this solution is that in this case rules used in decision-making will be subject to change by anyone at any time. This not only calls into question whether they can be considered to be rules at all, but also reproduces problems mentioned earlier: long-term commitments, trust, and expectations might break down if too many exceptions are granted, or rules are continuously changed.

Most two-level consequentialists, therefore, opt for a different alternative. Their idea is that, people should value decision-making rules for their own sake, i.e., they should look at them as constituting the true morality. They are not supposed to be aware of their merely instrumental nature. While this could guarantee that the rules are rarely broken, two further problems arise. First, we do not want inflexible rules; after all, one virtue of the consequentialist approach is that it is sensitive to changing empirical circumstances. This outcome could be avoided if we do give some people the right to change the rules. However, this does not affect the second problem: that on this view the true morality must not be publicly affirmed but must

\footnotetext{
${ }^{32}$ Nonetheless, we keep an open mind on these matters. As we are also open to changing the criterion of rightness from maximizing act-consequentialism to something else if that keeps in place as central the rule for individuals to set up and maintain institutions. Interesting candidates could be Regan's (1980) co-operative utilitarianism or Mendola's (2006) multiple-act consequentialism. One might also try to work out institutional consequentialism as an indirect view, along rule-consequentialist or other lines. See also footnote 24.
} 
be kept secret. All that is added is now that the secret morality will be safeguarded by a small elite of rulers who make sure that the correct rules are used via constant revisions and the requisite education and socialization of people. That is, we are forced to endorse what Sidgwick (1907: 489-90) - approvingly - called ‘Government House Utilitarianism'. However, most people find such a solution unpalatable (although others disagree, see Smith 1989; LazariRadek \& Singer 2010; Eggleston 2014).

We disagree about this assessment of the consequentialist's options. Concerning the first solution, we should not forget that our focus is on institutions. Most institutions have public rules of review and recognition: higher-order rules that tell subjects how to identify, review, and change rules. They also have rules concerning how they should be supported and what to do with citizens when they fail to support them. Of course, these rules too can be revised but their revision and change are normally made very difficult and subject to various conditions (think of constitutional amendment procedures). While this solution is not watertight, a sufficiently comprehensive institutional design can make sure that rules are not constantly changed and sufficient trust is created in the system without violating the publicity requirement.

Concerning the second solution, there is a way to reject the idea that people cannot pursue non-consequentialist decision rules for their own sake while also being aware of their instrumental nature. The idea is that some kind of compartmentalization is possible: judges do this all the time when they bracket their personal views in making decisions and Rawls's (1993) notion of public justification relies on a similar idea when it requires people not to introduce non-public justification in public debates. Hence, we conclude, either way there appears to be at least some hope for saving two-level institutional consequentialism. 


\section{Two objections}

So far we have described the demandingness objection to consequentialism (section 1), introduced institutional consequentialism as a response (sections 2-4), and further elaborated upon the exact structure of the view (section 5). In section 4 we have already responded to three immediate objections to our approach; it is now time to consider further problems. From the literature on Rawls's theory of justice, two objections seem to have clear relevance for us. First, Murphy (1998) has argued that demandingness considerations will not give us what he calls dualism - the Rawlsian idea that different principles apply to institutions and to individuals. And, the thought is, we need dualism in order to substantiate the present response to the demandingness objection. Second, consequentialism, unlike, for instance, the Rawlsian system appears to be a monist theory in the following sense: the same criterion of rightness applies to individuals as to institutions. Hence the dualist idea that is taken to underlie the present response to the demandingness objection may not be justifiable in the case of consequentialism.

Since we take the second problem to be more basic and our response to it will also help with the first problem, let us proceed in reverse order. Rawls and others following him indeed use consequentialism as the prime example of a comprehensive, monist theory: the principle of beneficence should apply both to institutional and to individual conduct. How can we deny this? But we think the relevant question to ask is: once we properly understand what it means for the principle of beneficence to apply to an agent, why shouldn't we deny it? The essential distinction to use here is once again between criterion of rightness and decision procedure. ${ }^{33}$

\footnotetext{
${ }^{33}$ Murphy's formulations of dualism are ambiguous about this point. Insofar as 'practical principle' in the first characterization (Murphy 1998: 254) refers to a criterion of rightness, as we shall presently point out, we do not deny monism, hence we do not consider ourselves to be dualist in this sense. However, we do deny what Murphy claims monism requires on his second characterization (271), i.e. that people must aim at whatever this moral criterion is. We have been arguing that people's responsibility is indeed mediated by institutions. It seems that Murphy is working here with an underlying assumption the denial of which is crucial for our proposal: that there is no distinction between criterion of rightness and decision procedure. This, however, is an unwarranted presupposition that Murphy does not argue for.
} 
On the view defended here, beneficence does not apply to individuals in the sense that it does not directly guide their action: it is not a decision rule for them. The maximization of the good often cannot and should not be what individuals aim at and this is true even of public officials on certain occasions. Beneficence provides decision-makers with a criterion for the moral assessment of alternative courses of action and the social planner for the design of institutions, but it doesn't provide a sufficiently action-guiding rule individuals are to follow. This is just what two-level institutional consequentialism is about. ${ }^{34}$

We suspect that something else lies behind the idea that consequentialism simply cannot be a dualist theory. We can see this by introducing a distinction discussed at length by Scheffler (2005). There are two versions of the idea of division of labour in Rawls's work. There is first a division of moral labour that urges us to have separate moral principles for institutions and individuals on the ground that they promote different moral values. Since the relevant moral values in the case of individuals also have to do with partial concerns - such as relationships or self-interest - this is indeed a division of labour that, it seems, consequentialism, being a thoroughly impersonal theory, cannot make use of; on this reading consequentialism must be a monist theory.

Recall, however, that we introduced the idea of a moral division of labour as one half of a distinction. ${ }^{35}$ As it happens, the other half - which Scheffler calls an institutional division of labour - is more suitable for consequentialist purposes. It relies on the idea that there are different rules for the design of the basic institutional structure of society and for individual conduct. The consequentialist moral criterion belongs to the first group for several reasons we discussed earlier (background adjustment and institution's constitutive role). It seems that

\footnotetext{
${ }^{34}$ Recall, though, that a duty to directly to promote the good is not entirely missing from our version of institutional consequentialism. We do allow, as we admitted and explained in more detail in sections 4 and 5 for a such a duty to come into effect; our claim is just that this would too rarely happen to make institutional consequentialism excessively demanding and a properly monist theory.

${ }^{35}$ A possible alternative line of response would be to argue that consequentialism is not necessarily impersonal in nature (cf. Hooker $2011 \mathrm{ab}$ ). But we let this go since there is a better answer (or at least a less committal one).
} 
institutional division of labour is all that we need to answer Murphy's challenge if interpreted as above.

We can also answer now Murphy's first objection: that demandingness considerations will not give us what he calls dualism, yet we need dualism in order to substantiate the present response to the demandingness objection. We accept the second half of Murphy's claim, so the question is: what supports the first half? At its core, his point is simple: it is perverse to require people to establish and maintain consequentialist institutions, but not require them to pursue the consequentialist aim personally. Our response to this is twofold. First, we do not need to claim that the demandingness objection is what justifies dualism for the consequentialist. As we just saw, there are good reasons to single out institutions as morally special that make a perfectly good case for why individuals shouldn't and - as far as the reasons above are concerned - couldn't pursue consequentialist aims individually. In short, our first claim is that we should endorse dualism for these (and perhaps other) reasons and this will still give us a response to the demandingness objection as a (perhaps unintended) side-effect of the division of labour that dualism secures for us.

Our second response is more tentative and uses an argument from Goodin (1995: 307). We take him to argue that the demandingness objection, contrary to what Murphy claims, does in fact require consequentialists to endorse institutional consequentialism. His argument appears to rely on a particular reading of the objection: that the claim that the consequentialist demand is a wrongful one is a plea for excuses - the excuse being that it is not the individual's job to fulfil the demand, yet, it is something that should be done. Goodin thinks that individuals do have this excuse available to them due to the absence of effective coordination on their level. This then exculpates individuals but, in turn, inculpates communities since the job has to be done and communities, in particular, their institutions, have the relevant formal coordination structures. This is a good argument, but a lot depends on whether Goodin is right about his 
reading of the demandingness objection: can consequentialists demonstrate that the "job has to be done" by someone? If they cannot, Goodin's argument collapses; if they can, we have a second answer to Murphy's challenge.

\section{The global application of institutional consequentialism}

There is still the question whether institutional consequentialism works also on the global level as a response to the Objection. Arguably, the demandingness objection is most persuasive when we appeal to existing global problems (e.g. poverty, peace and climate change). Does the institutional approach have the resources to respond to the objection in the face of global issues? If relevant institutions are missing but the tasks are formidable, an institutional division of labour cannot contain the demands individuals face.

Global problems are unlikely to render consequentialist requirements overly demanding. One reason for this is that the current global institutional framework can successfully mitigate consequentialist requirements. Elsewhere we argue that the status quo including institutions such as the nation-state system and supranational institutions allocates and coordinates responsibilities in a system of distributed obligations both horizontally (i.e., between states) and vertically (i.e., between states and supranational institutions). (blinded; Goodin 1988: 685). This institutionally regulated division of labour in turn reduces the burdens on individuals by spreading thin the burdens of compliance across a larger number of parties, by facilitating specialization in the performance of functionally defined tasks, by clearly allocating responsibilities and coordinating the manner in which agents implement them, and by providing assurance that responsibilities will be mutually honoured.

Furthermore, the current institutional framework can be reformed to better respond to global challenges. Piecemeal reforms are preferable to radical changes on consequentialist 
grounds, and they may further reduce consequentialist demands on individuals. ${ }^{36}$ For example, establishing inclusive procedural rules to increase the legitimacy of supranational institutions may make the latter more effective and at the same time reduce the motivational demands individuals face in the performance of their duty to support reform initiatives (blinded). Legitimacy is essential for institutions to generate their own support, and global institutions with weak legitimacy cannot effectively deal with moral disagreements, in particular disagreements about socioeconomic justice, that generate collective action problems and obstruct coordination. Making decision-making procedures within these institutions more inclusive can increase their legitimacy and thus reduce motivational demands individuals face in the collective pursuit of consequentialist aims.

The second reason for thinking that global moral requirements are not going to be so demanding as to invalidate the institutional defence of consequentialism is related to a point we made in Section 4 in the context of failed states. When the pursuit of gradual reforms through legitimate procedures is not feasible - since there are no workable institutions in place or current institutions are perceived as grossly unjust or illegitimate - individuals likely have no consequentialist duty to fight for institutional reform since global collective action problems make individual attempts at system change futile and wasteful.

This should not surprise consequentialists. Within consequentialist theories actionguiding requirements must be based on an assessment of what can be achieved, given the current state of the world, at what cost. Identifying the most cost-effective ways to improve the world will be to a large degree an empirical matter. In particular, the current global institutional framework should be used as a point of departure to determine consequentialist requirements. The institutional stance in the development economics literature provides support to the

\footnotetext{
${ }^{36}$ We discuss and evaluate such radical proposals - for example, that of setting up a world state or endorsing a neo-medieval institutional framework - in our $($ blinded $)$.
} 
position that regards global consequentialist requirements as limited. Since the quality of institutions is the primary determinant of economic development within countries, outside actors can at best help the global poor by providing assistance in building institutions, rather than by sending direct aid to improve welfare (Risse 2012: 68-69, 80). The upshot is that duties to provide international assistance are likely to be less demanding than might be thought or no duty will apply since what it takes to help the globally poorest cannot be done by outsiders.

To sum up: institutional consequentialism calls for a division of labour between individuals and institutions - this time on the global level. Individuals should promote the establishment and the reform of institutions that can solve global collective action problems and can specify and enforce duties for agents. Although identifying the most effective way to improve existing institutions in the current global framework - and the demands that come with it - is largely an empirical matter, there are good reasons to believe that the global institutional division of labour reduces burdens on individuals. Institutions provide assurance that others will contribute their share of the collective burden. They make it easier to do good by enforcing compliance with rules, and they change preferences to align individual interests with the overall good. Finally, they allow us to direct some of our attention and time to the pursuit of our personal projects and relationships.

The idea of a global division of labour invites an objection, however. Applying Murphy's second objection to the global case, it asks: Is it not perverse to require individuals to support institutions promoting the good without requiring them to promote the good directly? Rather than lobbying their governments to promote institutional change, they could surely do a lot more good by devoting their resources to charities that help the global poor directly. 
We disagree. ${ }^{37}$ It may be futile or worse, counterproductive, for individuals to directly pursue consequentialist aims rather than to support just institutions. We have already seen general reasons why this is so but in the global case there are further considerations to mention. For instance, when individual philanthropy through donations to NGOs replaces political action aimed at institutional reform, the proliferation of NGOs may break down coordination and exacerbate the global collective action problems we described earlier. Some critics of NGOs such as the Gates Foundation argue that their entry into the health care sector in third world countries has led to an internal brain drain of health personnel away from the public sector, resulting in suboptimal health outcomes (Daniels 2008: 330). More generally: foreign aid aimed at directly helping the global poor may make things worse through a mechanism similar to the so-called 'resource curse': it may generate rent-seeking by the elites and crowd out productive investments that are more desirable in the long run (Deaton 2013: 298). Individual philanthropy may also result in harmful long-term consequences by undermining public trust in political institutions and by weakening people's interest in political participation. If so, it forecloses the possibility of economic development benefiting the poor by precluding reforms necessary to fix underdeveloped countries' systems of public institutions and the international institutional structure (Deaton 2013). ${ }^{38}$ The only way outsiders can help the poor is often indirect: in line with institutional consequentialism, our duty is to assist in building good institutions. Demands imposed on individuals by their duty to make institutions more just in an international context are limited by what individuals can be expected to achieve, taking into account the lessons from the institutional stance in social science.

\footnotetext{
${ }^{37}$ Although, again, as we have repeatedly said: our version of institutional consequentialism doesn't en bloc rule out the existence of such an individual duty.

${ }^{38}$ It is for these reasons that critics of the Effective Altruism movement argue that the movement's focus on individual acts of charity is itself misguided. The focus of a proper consequentialist theory should be on systemic reforms rather than individual decisions about how to spend our spare money (Acemoglu 2015). For a defense of Effective Altruism (that we intend to discuss in a separate paper), see Berkey $(2016,2018)$.
} 


\section{Summary and concluding remarks}

There may be several good reasons to reject consequentialism. We have argued in this paper that demandingness is not one of them. The right approach to this problem is institutional. Once we realize that a division of labour between individuals and institutions is justified on good moral grounds that are also compatible with consequentialism, we will also see that putative features of consequentialism that many thought would impose excessive demands on individual agents will in fact arise on the level of institutional systems. Consequentialist demands on our time, attention and motivations need not undermine our ability to lead a life rich in personal projects and commitments. Our individuality need not be wiped away by impersonal calculating requirements on our decisions and actions. Our response to the Objection is consistent with consequentialism since it is not based on the independent moral status of values such as fairness, rights or freedom. Our preferred version of institutional consequentialism takes a two-level form with institutions, i.e., public system of rules designed to promote consequentialist aims but individuals - both private citizens and, on occasions at least, public officials - using non-consequentialist decision procedures. Finally, we have argued that although the global stage offers further challenges to our view, there are grounds to argue that these challenges can be diffused. No doubt, there are some questions left open in this yet, we submit, we have provided enough material to make one hopeful for the future of institutional consequentialism.

\section{Acknowledgments. $[\ldots]$}

\section{References}

Acemoglu, D. (2015), 'A Response to Peter Singer: The Logic of Effective Altruism', Boston Review, 40 (4)

Applbaum, A. (1999), 'Ethics in Equilibrium,' in Ethics for Adversaries, Princeton, NJ: Princeton University Press 
Bailey, J.W. (1997), Utilitarianism, Institutions, and Justice, Oxford: Oxford University

Press

Berkey, B. (2016), 'Against Rawlsian Institutionalism about Justice', Social Theory and Practice 43 (4): 706-732

Berkey, B. (2018), 'The Institutional Critique of Effective Altruism', Utilitas 30 (2): 143-171.

Bykvist, K. (2009), Utilitarianism: A Guide for the Perplexed. London: Continuum.

Carter, A. (2009); 'Is Utilitarian Morality Necessarily too Demanding?', in T. Chappell (ed.), The Problem of Moral Demandingness: New Philosophical Essays, London: Palgrave MacMillan. pp. 163-185

Cullity, G. (2004), The Moral Demands of Affluence. Oxford: Clarendon Press

Daniels, N. (2008), Just Health, Cambridge: Cambridge University Press

Deaton, A. (2013), The Great Escape, Princeton: Princeton University Press

Dorsey, D. (2016), The Limits of Moral Authority, Oxford: Oxford University Press

Hare, R. M. (1981). Moral Thinking, Oxford: Clarendon Press

Eggleston, B. (2014), 'Act Utilitarianism', in. B. Eggleston and D. Miller (eds.), The Cambridge Companion to Utilitarianism, Cambridge: Cambridge University Press, pp. 124145

Goodin, R. (1988), 'What is So Special about Our Fellow Countrymen?' Ethics, vol.98 no.4, pp. $663-686$

Goodin, R. (1995), Utilitarianism as a Public Philosophy, Cambridge: Cambridge University Press

Goodin, R. (2009), 'Demandingness as Virtue', Journal of Ethics 13: 1-13

Hardin, R. (1986), 'The Utilitarian Logic of Liberalism', Ethics 97: 47-74

Hardin, R. (1988), Morality Within the Limits of Reason, Chicago, Ill.: University of Chicago Press

Hayek, F.A. (1976), Law, Legislation and Liberty: A New Statement of the Liberal Principles of Justice and Political Economy, Volume II. The Mirage of Social Justice, Chicago, Ill.: University of Chicago Press

Hooker, B. (2009). 'The Demandingness Objection', in T. Chappell (ed.), The Problem of Moral Demandingness: New Philosophical Essays, London: Palgrave MacMillan. pp. 148-163 Hooker, B. (2011). 'Promises and Rule Consequentialism', in Sheinman, H. (ed.) Promises and Agreements: Philosophical Essays. Oxford University Press, USA, pp. 235-252.

Hooker, B. (2011). 'When Is Impartiality Morally Appropriate?' in Feltham, B. M. and Cottingham, J. G. (eds.) Partiality and Impartiality: Morality, Special Relationships and the Wider World. Oxford: Oxford University Press, pp. 26-41.

Kymlicka, W. (2002), Contemporary Political Philosophy, Oxford: Oxford University Press Lazari-Radek, K. \& Singer, P. (2010), 'Secrecy in Consequentialism: A Defence of Esoteric Morality', Ratio 23: 34-58

McElwee, B. (2011). 'Impartial Reasons, Moral Demands', Ethical Theory and Moral Practice 14: 457-466.

Mendola, J. (2006), Goodness and Justice, Cambridge: Cambridge University Press

Miller, S. (2010), The Moral Foundations of Social Institutions, Cambridge: Cambridge University Press.

Mulgan, T. (2001), The Demands of Consequentialism. Oxford, UK: Clarendon Press.

Mulgan, T. (2007), Understanding Utilitarianism. London: Acumen.

Murphy, L. D. (1998), 'Institutions and the Demands of Justice', Philosophy and Public Affairs, 27(4): 251-291.

Murphy, L. D. (2000). Moral Demands in Non-ideal Theory, Oxford: Oxford University Press Nagel, T. (1979), 'Ruthlessness in Public Life', in Mortal Questions, Cambridge: Cambridge University Press, pp. 75-91 
Nagel, T. (1991), Equality and Partiality, New York: Oxford University Press

Norcross, A. (2006). 'Reasons Without Demands: Rethinking Rightness', in. James Dreier (ed.), Contemporary Debates in Moral Theory, pp. 38-53, Oxford: Blackwell

North, D. (1990), Institutions, Institutional Change, and Economic Performance, Cambridge:

Cambridge University Press

Nussbaum, M. (2007), Frontiers of Justice: Disability, Nationality, Species Membership, Cambridge, Mass.: Harvard University Press.

Pogge, T. (1989), Realizing Rawls, Ithaca: Cornell University Press.

Pogge, T. (2008), World Poverty and Human Rights $2^{\text {nd }}$ ed., Cambridge; Polity Press.

Portmore, D.W. (2011), Commonsense Consequentialism: Wherein Morality Meets Rationality, Oxford: Oxford University Press

Railton, P. (1984) 'Alienation, Consequentialism, and the Demands of Morality', Philosophy and Public Affairs, 13: 134-171

Rawls, J. (1955), 'Two Concepts of Rules', Philosophical Review 64 (1): 3-32

Rawls, J. (1971), A Theory of Justice, Cambridge, MA: Harvard University Press

Rawls, J. (1993), Political Liberalism, New York: Columbia University Press

Rawls, J. (1999), The Law of Peoples, Cambridge MA: Harvard University Press

Regan, D. (1980), Utilitarianism and Cooperation, Oxford: Clarendon Press

Risse, M. (2012), On Global Justice, Princeton: Princeton University Press

Sandberg, J., \& Juth, N. (2011), 'Ethics and Intuitions: A Reply to Singer', Journal of Ethics, 15 (3): 209-226

Scheffler, S. (2005), 'The Division of Moral Labour: Egalitarian Liberalism as Moral

Pluralism', Proceedings of the Aristotelian Society, Supplementary Volume 79: 229-253.

Sidgwick, H. (1907), The Methods of Ethics (7th ed.), London: Macmillan

Smart, J.J.C. (1956), 'Extreme and Restricted Utilitarianism', Philosophical Quarterly 6 (25): 344-354

Smith, H.M. (1988), 'Making Moral Decisions', Noûs 22(1): 89-108

Smith, H.M. (1989), 'Two-Tier Moral Codes', Social Philosophy and Policy 7 (1): 112-132

Valentini, L. (forthcoming), 'The Natural Duty of Justice in Non-Ideal Circumstances: On the Moral Demands of Institution Building and Reform', European Journal of Political Theory, Online First, accessed at 09/07/2018

Wolf, S. (1982), 'Moral Saints', Journal of Philosophy, 79: 419-439 